
аспекты поведения теплоносителя в циркуляционных петлях реакторной установки при взаимодействии с борным раствором, который подается в первый контур насосами системы аварийного охлаждения зоны (САО3).

Интегральные компьютерные модели реакторных установок (РУ) для расчетных теплогидравлических кодов (например, RELAP5/MOD3.2) позволяют получить только Моделирование температурного расслоения в главном циркуляционном трубопроводе

\title{
при естественной
}

циркуляции теплоносителя первого контура для оценки термошока корпуса реактора с помощью кода RELAP5/MOD3.2

Проведено разбиение холодных и горячих ниток модели реактора ВBЭP-1000 для компьютерного кода RELAP5/MOD3.2 на два уровня повысоте сцелью моделирования стратифицированных течений в главном циркуляционном трубопроводе при подаче воды от системы охлаждения активной зоны. Модель протестирована с использова нием экспериментальныхданныхпо перемешиванию и стратификации в холодной нитке. Сравнение результатов расчета течи с незакрытием предохранительного клапана компенсатора давления с экспериментальными данными показало улучшение описания переходного процесса. Модель может применяться для оценки явлений при ожидаемой термической стратификации теплоносителя в холодных нитках.

Ключевые слова: стратификация потоков, расчетная модель, перемешивание, термошок, термоудар, компьютерная модель, расчетный код, валидация.

\section{Ю. Ю. Воробйов, І. А. Терещенко}

Моделювання температурного розшарування в головному циркуляційному трубопроводі за природної циркуляції теплоносія першого контуру для оцінки термошоку корпусу реактора за допомогою коду RELAP5/MOD3.2

Проведено розбиття холодних та гарячих ниток моделі реактора BBEP-1000 для комп'ютеронго коду RELAP5/MOD3.2 на два рівні за висотою для моделювання стратифікованих течій в головному циркуляційному трубопроводі в разі подачі води від системи охолодження активної зони. Модель протестовано з використанням експериментальних даних щодо перемішування та стратифікації в холодній нитці. Порівняння результатів розрахунку течі з незачиненням запобіжного клапана компенсатора тиску з експериментальними даними показало покращення опису перехідного процесу. Модель може застосовуватися для оцінки явищ за очікуваної термічної стратифікації теплоносія в холодних нитках.

Ключові слова: стратифікація потоків, розрахункова модель, перемішування, термошок, термоудар, комп'ютерна модель, розрахунковий код, валідація.

() Ю. Ю. Воробьев, И. А. Терещенко, 2013 расчетному объему, в то время как интерес представляет именно информация по локальным значениям параметров теплоносителя, борного раствора и их смеси.

Расчетная модель реактора ВВЭР-1000 для кода RELAP5/Mod3.2 [1, 2] доработана путем детального квазидвумерного моделирования опускного участка с использованием технологии параллельных каналов. Для исследования возможности моделирования перемешивания внутри холодных и горячих ниток дополнительно внесены изменения в нодализацию данного оборудования. Примененный подход двухуровневого моделирования петель главных циркуляционных трубопроводов (ГЦТ) показывает определенные результаты, но имеет и свои ограничения. В представленной работе исследуется поведение данной модели, проводится оценка области ее возможного применения и ограничения.

Явление температурного расслоения в петлях ГЦТ. Эффекты стратификации и неполного перемешивания, а также картины сложного перемешивания теплоносителя существуют во многих состояниях РУ. Это возможно при подаче холодной воды САОЗ в петлю ГЦТ с низкой скоростью циркуляции, что, при определенных условиях, приводит к термогравитационному расслоению потока в петле (рис. 1). При попадании такого потока в опускной участок реактора в зависимости от скорости циркуляции наблюдается различная картина дальнейшего движения теплоносителя, определяемая импульсом самого потока, а также скоростью движения окружающей среды опускного участка.

В реакторах ВВЭР при попадании холодного языка в область гидрозатвора петли через проточную часть ГЦН более тяжелая холодная вода накапливается в гидрозатворе (рис. 1), что приводит к невозможности однофазной циркуляции по данной петле. Данный эффект предполагается по данным реального инцидента с незакрытием предохранительного клапана компенсатора давления (ПК КД) на энергоблоке № 3 Ривненской АЭС [3] и подтверждается стендовыми испытаниями на установке APEX [4].

Аналогичные случаи возникают в соединительных трубопроводах КД (дыхательный трубопровод). При этом горячая вода из КД расслаивается в горизонтальных участках трубопровода, что приводит к пульсациям температуры, сказываясь на тепловой усталости материалов [5].

Результаты попадания холодной воды в гидрозатвор холодной нитки при подаче воды с более высокой плотностью в прямой участок петли наглядно представлены в [6]. Важным является наличие восходящего и нисходящего потоков жидкости в опускной части гидрозатвора, что и приводит к перемешиванию и попаданию в него более холодной воды.

Критерии перемешивания в условиях естественной циркуляции в петле с подачей от САОЗ. Явление перемешивания в петлях ГЦТ при низкой скорости циркуляции или ее останове неотделимо связано с явлением перемешивания в опускном участке реактора. Подача воды САО3 в месте впрыска задает граничные условия для дальнейшего 


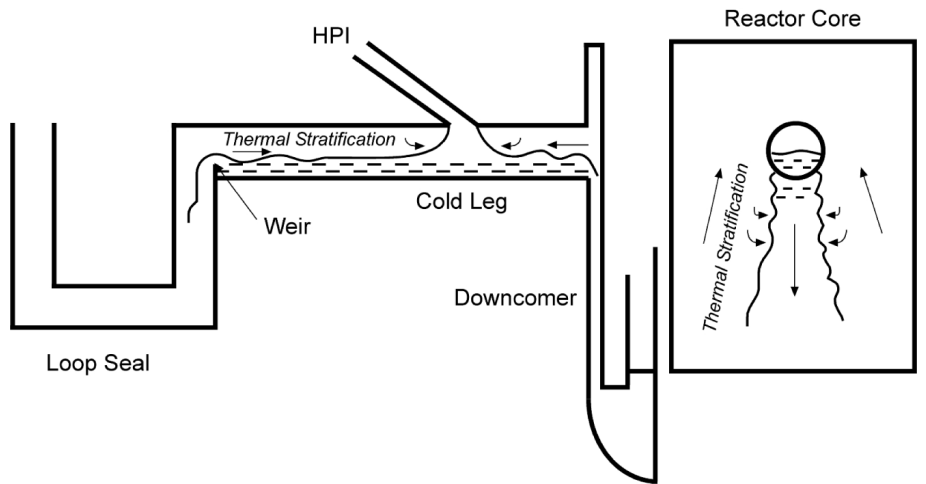

Рис. 1. Эффекты стратификации и перемешивания в первом контуре реакторной установки при подаче воды САОЗ [6]

поведения потока по пути к входному патрубку реактора и далее вниз по опускному участку. Применительно к геометрии реактора и холодной нитки при определенных расходах воды в ГЦТ возникает встречное течение. Верхнюю часть сечения ГЦТ занимает поток горячего теплоносителя из опускного участка, а нижнюю - поток холодной воды. Перемешивание воды САО3 и горячей воды происходит в основном в области впрыска воды САОЗ. Данное расслоение появляется при низкой скорости холодной жидкости, которая входит в трубопровод с горячей жидкостью [7, 8].

Перемешивание в точке впрыска воды САОЗ зависит от числа Фруда для впрыска и геометрии подводящего патрубка [9]. Численным критерием перемешивания является отношение обратного расхода (отношение расхода горячей воды верхнего слоя $Q_{h}$, поступающего из опускного участка реактора, к расходу воды САОЗ $\left.Q_{H P I}\right)$, или коэффициент перемешивания (entrainment coefficient):

$$
e=\frac{Q_{h}}{Q_{H P I}}
$$

На рис. 2 представлена зависимость данного коэффициента от модифицированного числа Фруда, которое определяется как

$$
\operatorname{Fr}_{H P I / C L}=\frac{Q_{H P I}}{a_{C L}\left[g D_{C L} \frac{\rho_{H P I}-\rho_{C L}}{\rho_{H P I}}\right]^{\frac{1}{2}}},
$$

где $Q_{H P I}-$ объемный расход подачи САОЗ ВД, $\mathrm{m}^{3} / \mathrm{c} ; a_{C L}-$ площадь сечения холодной нитки, ${ }^{2} ; D_{C L}-$ диаметр холодной нитки, м; $\rho_{C L}, \rho_{H P I}-$ плотность воды в холодной нитке и воды САОЗ, кг/м $; g=9,8066$ м/ $\mathrm{c}^{2}-$ ускорение свободного падения.

Аналогичные экспериментальные данные представлены в [10] для стендовой установки UPTF при различных комбинациях расхода $\mathrm{CAO} 3$ и разности плотностей. Упрощенно можно считать, что после перемешивания вода подается в опускной участок с температурой

$$
T_{m i x}=\frac{e T_{h}+T_{H P I}}{1+e}
$$

где $T_{h}, T_{H P I}-$ температура горячей воды опускного участка и САОЗ, соответственно; $T_{m i x}-$ результирующая

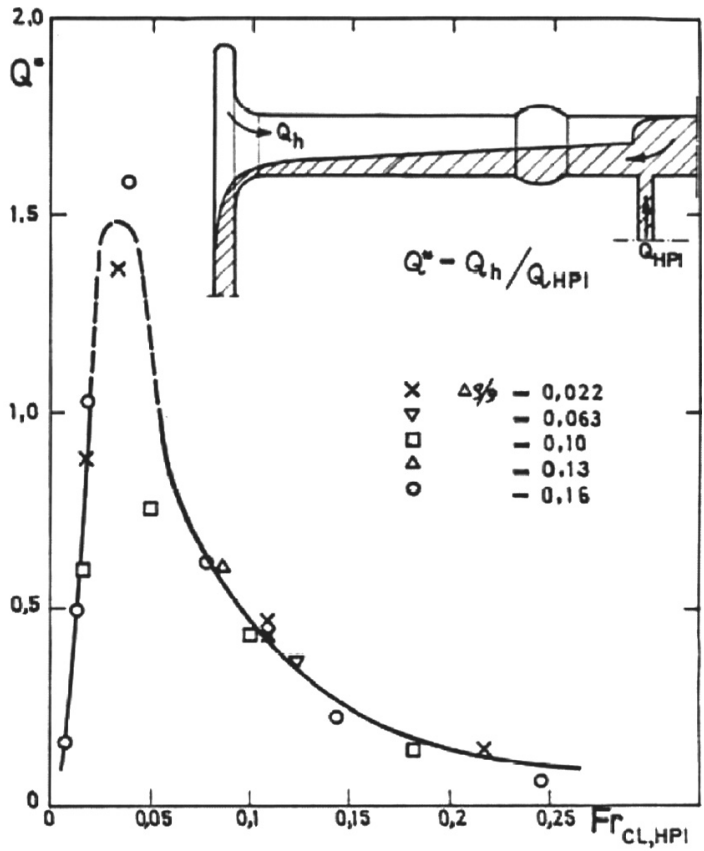

Рис. 2. Зависимость коэффициента перемешивания от модифицированного числа Фруда

температура воды, попадающей в опускной участок. Для более точного расчета необходимо учитывать энтальпию смешивающихся потоков.

При наличии расхода в петле с подачей воды САОЗ картина перемешивания может меняться в зависимости от импульса потока. Экспериментально определены соответствующие критерии по расходу в холодной нитке, ниже которого начинается стратификация потока в холодной нитке:

критерий 1 (Theofanous $[11,12])-$

$$
\mathrm{Fr}_{H P I / C L}=\left[1+\frac{Q_{L}}{Q_{H P I}}\right]^{-\frac{7}{5}}
$$

критерий 2 (Reyes [13]) -

$$
\operatorname{Fr}_{H P I / C L}=\left[1+\frac{\rho_{L} Q_{H P I}}{\rho_{H P I} Q_{L}}\right]^{-\frac{1}{2}} \cdot\left[1+\frac{Q_{L}}{Q_{H P I}}\right]^{-\frac{3}{2}},
$$

где $Q_{L}$ и $\rho_{L}-$ объемный расход и плотность в холодной нитке, соответственно.

При больших расходах в холодной нитке перемешивание происходит равномерно по сечению и стратификация исчезает.

Модель ГЦТ и реактора. Для разбиения холодных ниток ГЦТ применялось расположение горизонтальных объемов половинного сечения ГЦТ с разностью их высотных отметок $0,85 / 2=0,425$ м. Объемы связывались поперечными связями для имитации перемешивания. Разбиению подвергались холодные нитки, включая ГЦН и гидрозатворы (рис. 3, 4). Разбиение горячих ниток проведено аналогично, однако соединение с реактором произведено на одном уровне (рис. 5, 6). Данный способ позволяет учесть перемешивание петли, однако не в полной мере учитывает расслоение в горячих нитках. На входе в реактор проведено аналогичное разбиение по высоте входного объема. 
Рис. 3. Нодализация холодной нитки петли № 1 базовой модели
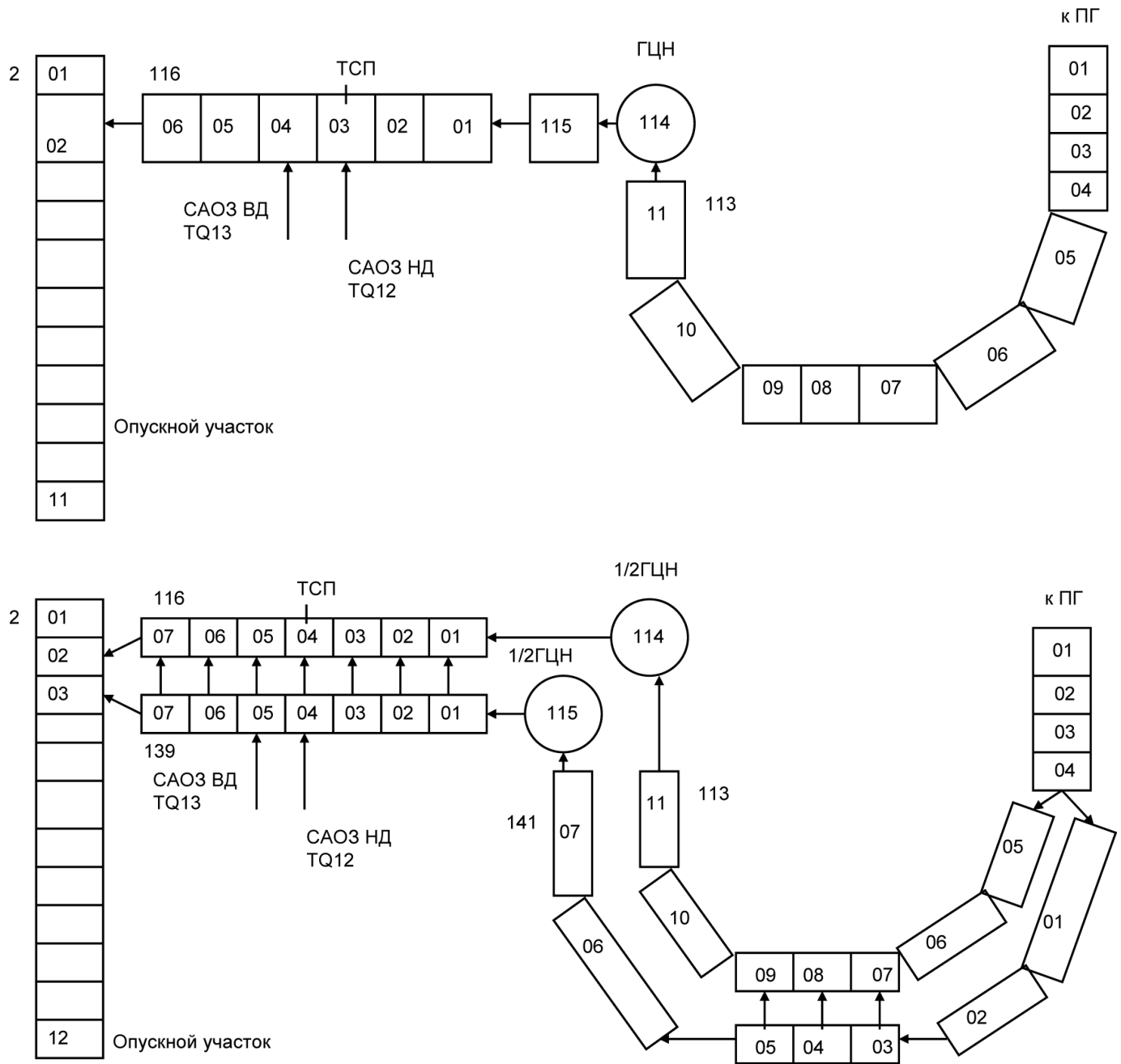

Рис. 4. Нодализация холодной нитки петли № 1 для двухуровневой модели

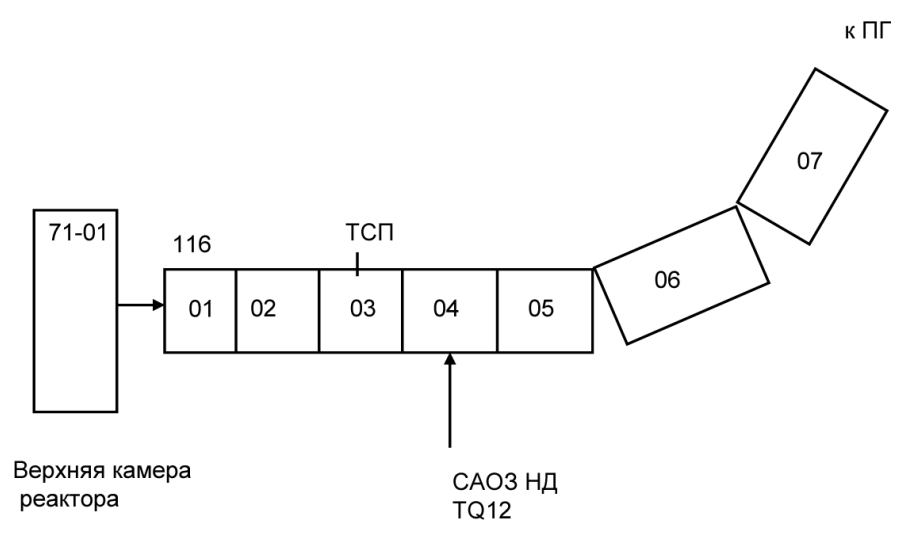

Рис. 6. Нодализация горячей нитки петли № 1 для двухуровневой модели
Рис. 5. Нодализация горячей нитки петли №

базовой модели

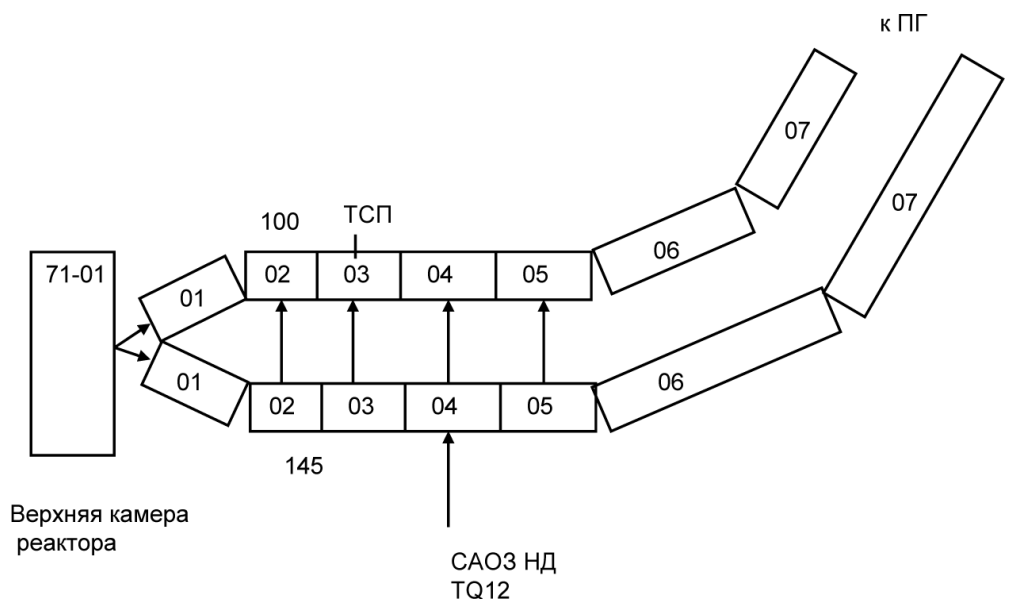




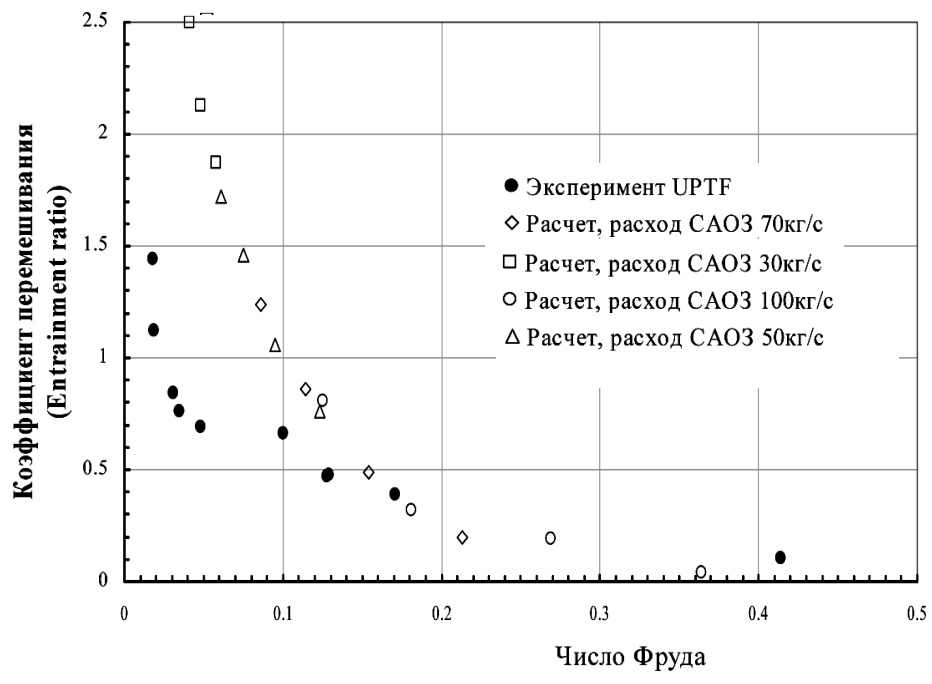

Рис. 7. Коэффициент перемешивания при впрыске воды САОЗ в холодную нитку в условиях стагнации потока

Необходимость вовлечения в перемешивание гидрозатвора потребовала разбиения соответствующего участка также на два уровня. Площадь поперечных связей равна сечению ГЦТ в поперечном направлении с коэффициентом гидравлического сопротивления (КГС) связей 0,01 и отключенным учетом импульса (флаг $s=3$ ). Анализ чувствительности к КГС поперечной связи показал малое влияние на скорости перемешивания, поэтому, исходя из физической необоснованности более высоких значений, решено оставить данное значение КГС.

Главные циркуляционные насосы (ГЦН) разделены на две компоненты с уменьшенным в два раза расходом и объемом. Два ГЦН в модели петли вращаются синхронно и имеют одинаковые сигналы. Сравнение переходного процесса с выбегом ГЦН и естественной циркуляцией показало полную идентичность картины с базовой моделью.

Для модели горячих ниток применен аналогичный подход, при котором искусственно перемешивается горячая нитка с выходным объемом реактора (рис. 6.). При этом участки двух уровней модели горячей нитки присоединяются к одному объему на выходе реактора. Данный способ применен из-за нецелесообразности разбиения реактора на этом уровне на дополнительное количество объемов для точного учета разности высотных отметок. Тестирование данной модели на отдельных граничных условиях указывает на стабильное перемешивание горячей нитки с выходным объемом реактора. Однако данный подход имеет недостаток - значения температуры верха и низа горячей нитки практически совпадают.

Присоединение САОЗ к трубопроводам соответствует реальному положению патрубков. Определено, что модель CAO3 высокого давления (ВД) показывает стабильные физичные результаты при соединении с боковой гранью нижнего уровня модели холодной нитки. Расположение точек замера температуры выбрано в объемах до патрубка САОЗ ВД.

Описание модели реактора представлено в $[1,2]$. Разбиение опускного участка произведено азимутальным разделением на 20 вертикальных каналов (по пять на каждый из четырех секторов) с соединением поперечными связями

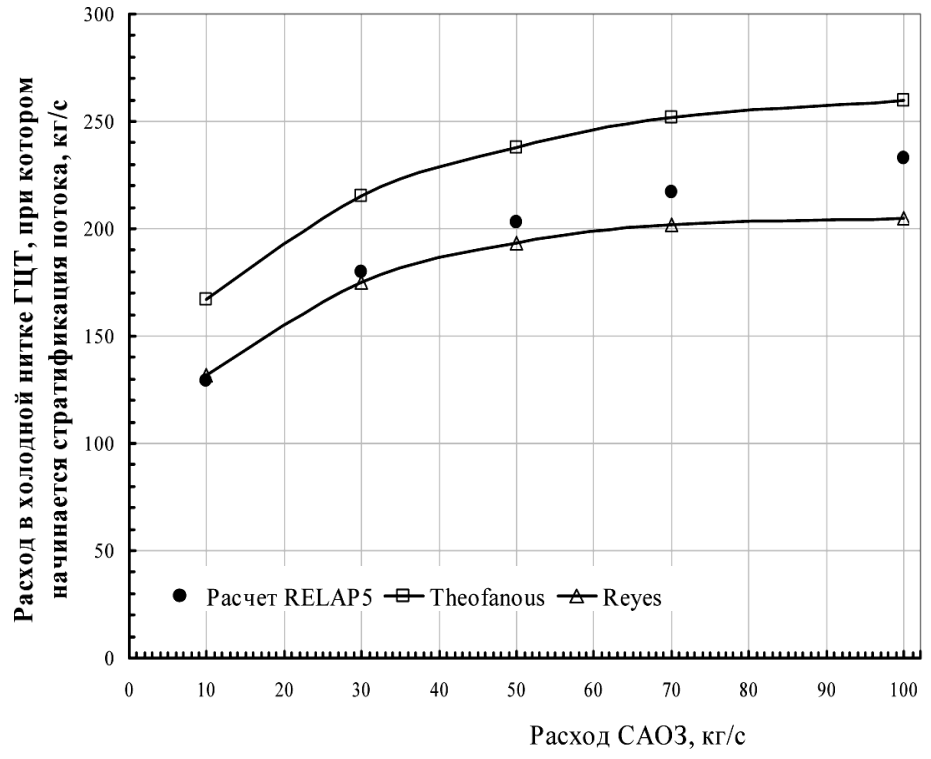

Рис. 8. Оценка момента начала стратификации при подаче воды САОЗ в холодной нитке с расходом теплоносителя

Сборка, настройка модели, качественная и количественная проверка явления стратификации. Настройка гидравлических характеристик тракта реактора совместно с первым контуром показала необходимость минимальной корректировки сопротивления на входе в реактор. Остальные гидравлические условия соответствуют базовой модели $[1,2]$. Проверка модели ГЦТ при низких скоростях циркуляции совместно с реактором показала стабильное отсутствие вторичных течений. Заданная стратификация теплоносителя в ГЦТ (горячий верх, холодный низ) поддерживается стабильно. Сравнительный анализ процессов с отключением ГЦН в базовой модели и в модели с двухуровневыми петлями показал практически идентичность расходов по тракту первого контура.

Для оценки картины циркуляции в холодной нитке при подаче воды CAO3 в условиях стагнации была поставлена модельная задача. На граничных условиях в одну петлю ГЦТ производился впрыск воды САОЗ ВД температурой $30{ }^{\circ} \mathrm{C}$. Начальные условия в петле соответствовали темпе-

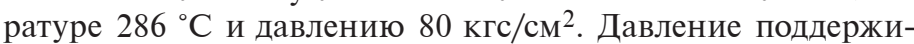
валось постоянным. Остальные петли отключались. По данным расходов определялся коэффициент перемешивания (рис. 7), который потом сравнивался с аналогичными экспериментами на установке UPTF [10].

Из рисунка видно, что при малых расходах впрыска САО3 модель обладает более сильным перемешиванием. При расходах около 50 кг/с и выше совпадение можно считать удовлетворительным.

Аналогично были проведены на граничных условиях тесты по проверке начала стратификации потока в петле при подаче САОЗ совместно с расходом по холодной нитке. Примененные критерии описаны выше. Для определения момента начала стратификации в холодной нитке с постоянным впрыском от САОЗ осуществлялось постепенное линейное во времени снижение общего расхода в холодной нитке. За момент начала стратификации принимался момент начала снижения температуры в объеме до патрубка впрыска CAO3 (начало течения нижней части холодной нитки в обратном направлении). На рис. 8 представлены результаты тестовых расчетов в сравнении с двумя 


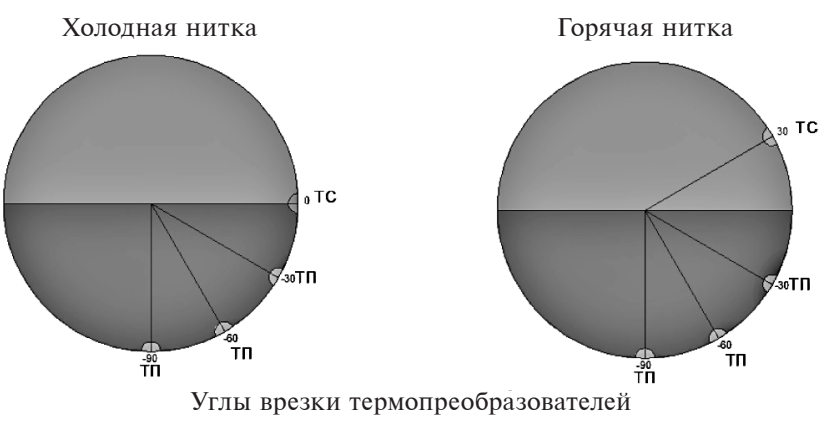

Рис. 9. Азимутальное расположение штуцеров на трубопроводе ГЦТ для подключения станционных термодатчиков

корреляциями. Видно, что для выбранного интервала расходов совпадение достаточно хорошее, результаты расчета укладываются в область между двумя выбранными корреляциями.

Расчетная проверка модели по экспериментальным данным. Для расчетной проверки измененной модели РУ с реактором ВВЭР-1000 выбирается нарушение «Незакрытие главного предохранительного клапана ИПУ КД YP21S01 во время плановой проверки работоспособности реальным повышением давления в первом контуре перед пуском энергоблока № 3 после ППР из-за подклинивания в седле золотника импульсного клапана YP21S04 после его открытия» [4]. Моделирование переходного процесса повторяет путь валидационного анализа, подробно изложенного в [1] и [14]. Данное нарушение характеризуется: поведением РУ при течи первого контура из парового пространства КД;

работой каналов САОЗ ВД;

работой каналов САОЗ низкого давления (НД).

Расположение термопар и термосопротивлений в ГЦТ указано на рис. 9.

Сравнение данных расчетного анализа с показаниями термодатчиков АЭС для петли № 1 представлено на рис. 10-13 (ТC, ТР означает термопару, TR - термосопротивление). Как указано ранее, термосопротивление расположено выше по отметке сечения ГЦТ, поэтому его показания сравниваются с температурой жидкости в верхнем объеме модели.

Видно, что показания модели улучшились, однако перемешивание происходит более интенсивно. Это проявляется в более интенсивном снижении температуры, что особенно выражено на этапе короткой подачи от САОЗ ВД. На этапе продолжительной подачи (2000-3500 с) совпадение можно считать удовлетворительным. Величина разности температуры верх-низ в холодной нитке в этом случае определяется достаточно корректно.

Сравнение данных расчетного анализа с показаниями термодатчиков АЭС для петли № 2, в которую не происходит подача воды САОЗ, представлено на рис. 14 и 15. В этом случае перемешивание происходит через общие объемы на входе в реактор. Как видно из результатов, представленных на рис. 14, базовая модель не отражает корректно поведение температуры. Разбиение холодных ниток позволяет учесть перемешивание и приводит к более корректному поведению температуры жидкости в холодной нитке (рис. 15).

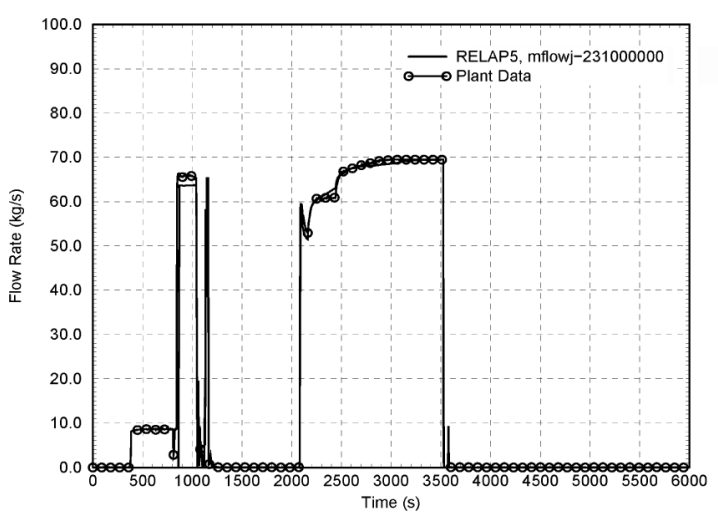

Рис. 10. Расход насоса САОЗ ВД TQ13D01

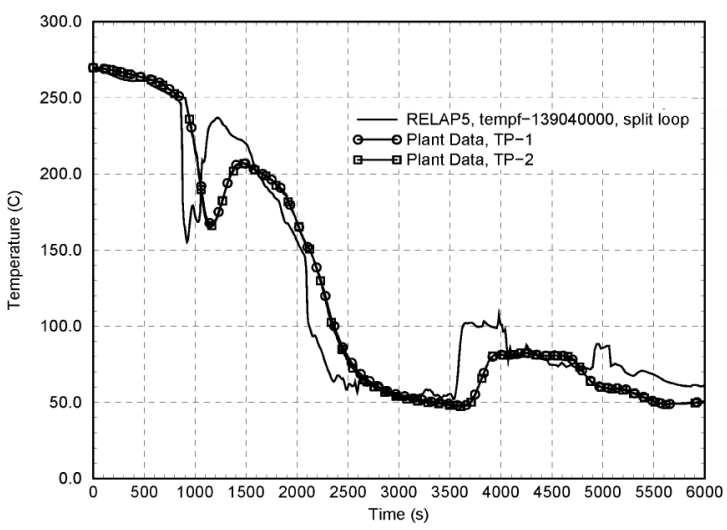

Рис. 12. Температура в холодной нитке петли № 1 (нижний объем двухуровневой модели)

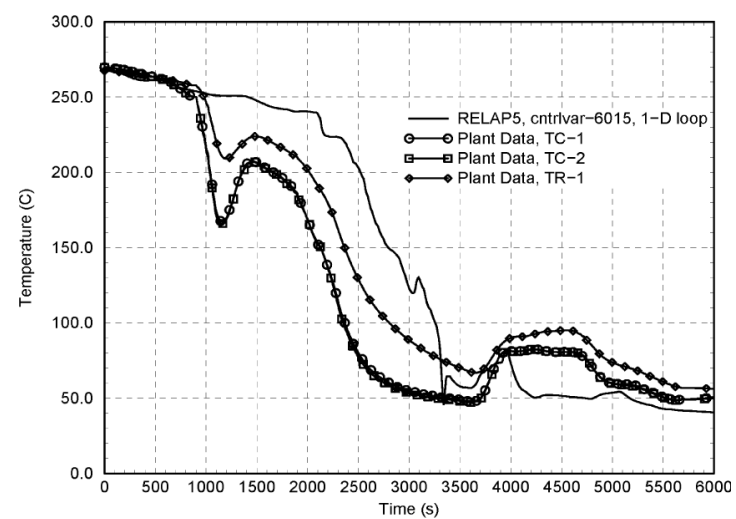

Рис. 11. Температура в холодной нитке петли № 1 (базовая модель)

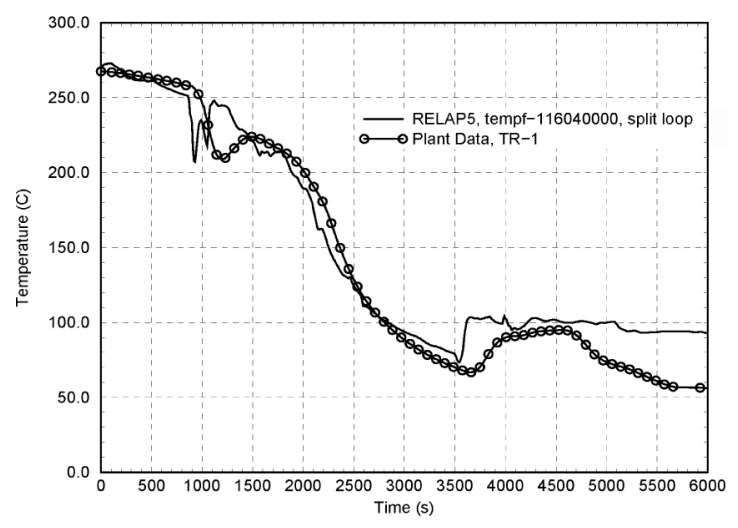

Рис. 13. Температура в холодной нитке петли № 1 (верхний объем двухуровневой модели) 


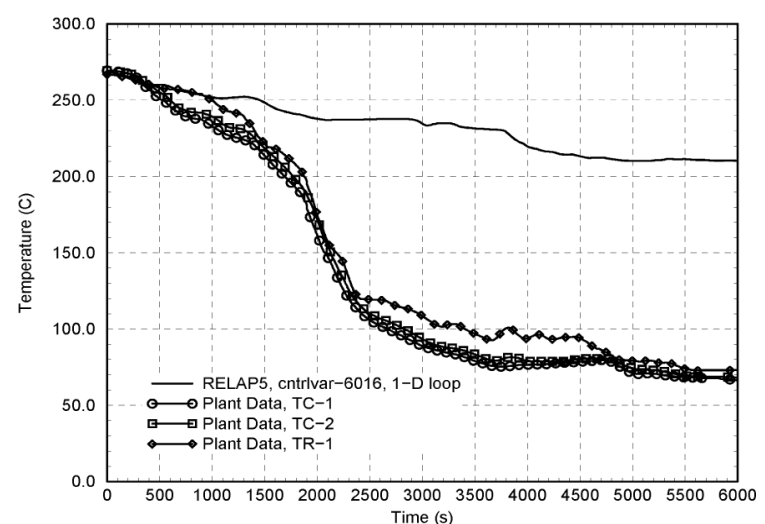

Рис. 14. Температура в холодной нитке петли № 2 (базовая модель)

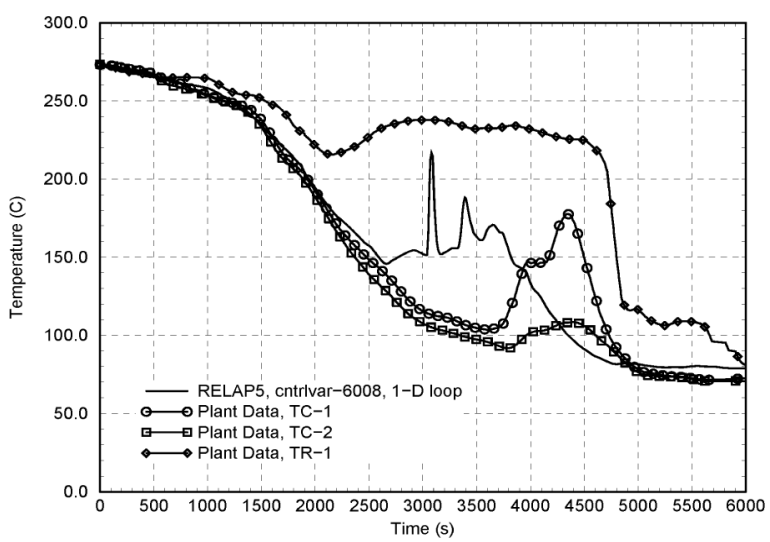

Рис. 16. Температура в горячей нитке петли № 4 (базовая модель)

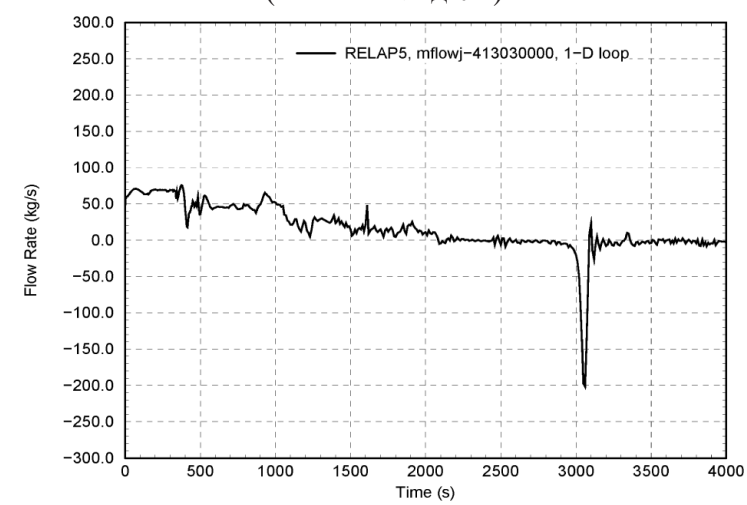

Рис. 18. Расход в холодной нитке петли № 4 (базовая модель)

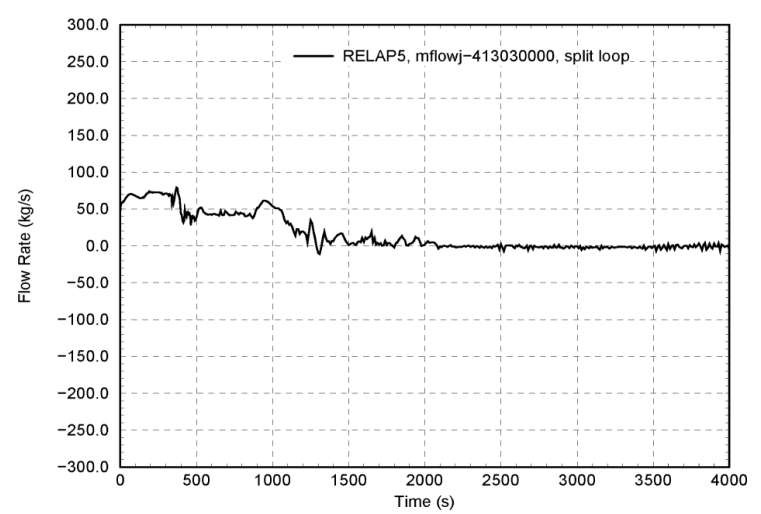

Рис. 20. Расход в холодной нитке петли № 4 (двухуровневая модель)

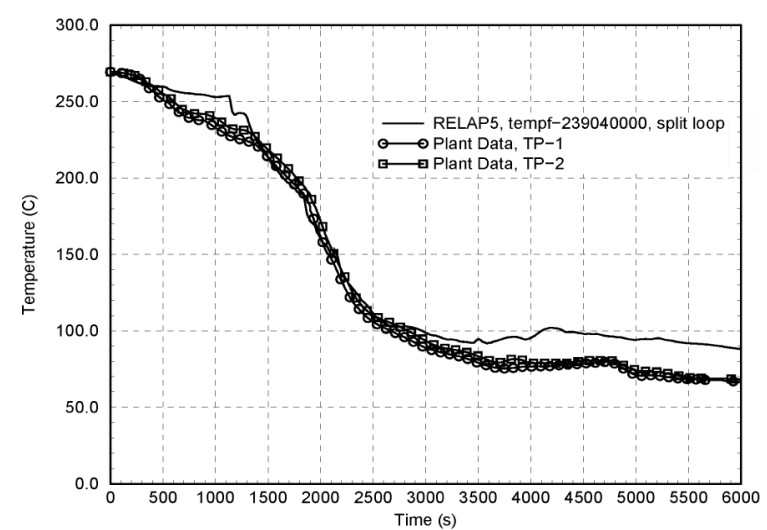

Рис. 15. Температура в холодной нитке петли № 2 (нижний объем двухуровневой модели)

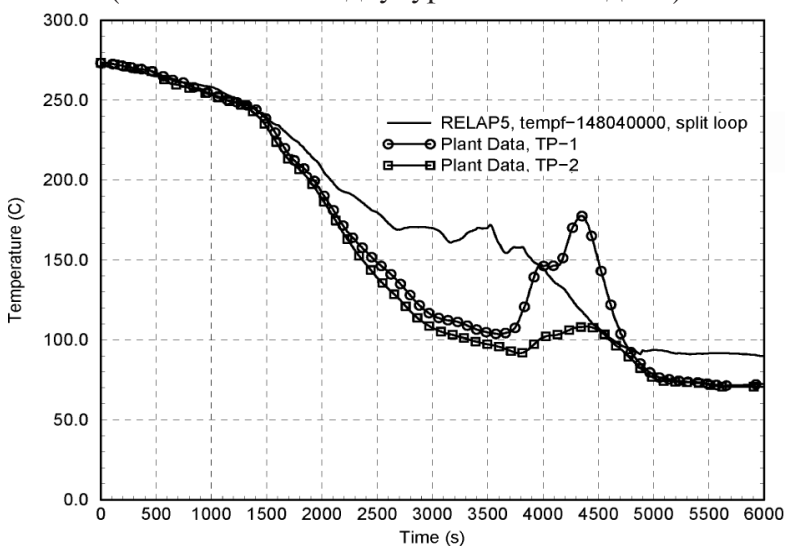

Рис. 17. Температура в горячей нитке петли № 4 (нижний объем двухуровневой модели)

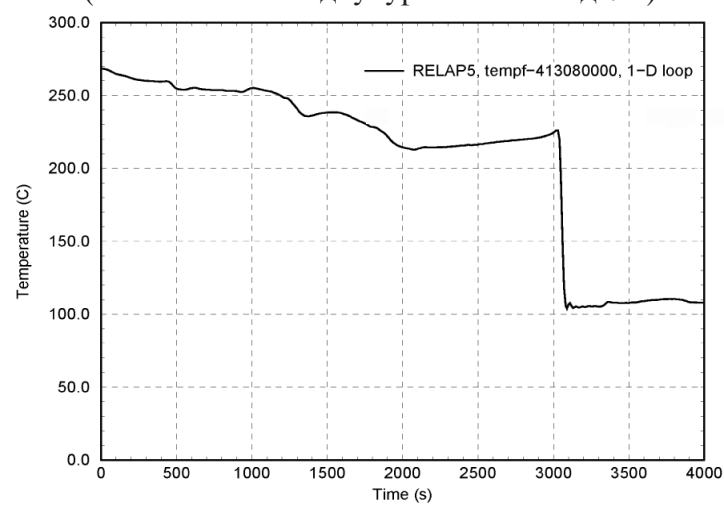

Рис. 19. Температура в гидрозатворе петли № 4 (базовая модель)

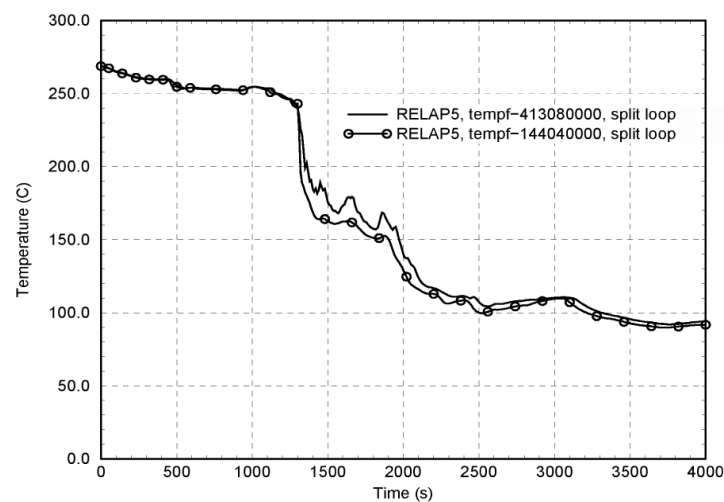

Рис. 21. Температура в гидрозатворе петли № 4* (двухуровневая модель)

* Представлены значения температур в верхнем и нижнем объемах. 
На примере горячей нитки № 4 рассмотрим поведение температуры жидкости (рис. 16 и 17). Температура горячей петли в расчетном анализе находится между показаниями термопар и сопротивлений (рис. 17), что указывает на полное перемешивание. Данный факт обусловлен способом подключения модели реактора к петле. Более того, принятая дискретизация модели и сам расчетный код не могут отследить резкий фронт между холодным и горячим теплоносителем, который появляется на уровне горячих патрубков. Именно этот фронт приводит к расслоению теплоносителя в горячей нитке с разностью температуры верхнего и нижнего слоя до $140{ }^{\circ} \mathrm{C}$.

Отсутствие возможности моделировать такое резкое разделение холодного и горячего теплоносителя в петле приводит к более высокой температуре воды в КД по сравнению с данными АЭС. Это, в свою очередь, влияет на характеристики истечения через ПК. Данные градиенты температур по сечению ГЦТ необходимо учитывать при прочностном расчете ГЦТ.

Эффект захолаживания гидрозатвора и образование «холодных пробок». Следствием одномерности холодных ниток и чрезмерного их захолаживания в базовой модели при подаче от САО3 является возможность разворота циркуляции во всей нитке в целом (рис. 18). При этом холодная вода попадает в гидрозатвор, что приводит к не наблюдаемому в реальности скачкообразному изменению температур петель и температур на выходе активной зоны (рис. 19). Двухуровневый подход к нодализации позволил перемешивать воду в гидрозатворе без соответствующего изменения общего расхода в петле (рис. 20), что приводит к постепенному заполнению гидрозатворов петель РУ и отсутствию колебаний расхода (рис. 21).

Сравнение эффекта захолаживания опускного участка реактора для модели с одно- и двухуровневым ГЦТ. Повышенное перемешивание при двухуровневом моделировании холодных ниток петель ГЦТ ожидаемо приводит к меньшей подаче холодной воды в опускной участок реактора при подаче САОЗ. Сравнение с базовой моделью указывает на более мягкие условия охлаждения области под патрубком ГЦТ (рис. 22). Сравнение средней температуры на выходе активной зоны указывает на хорошее соответствие с данными АЭС на начальной фазе. На протяжении инцидента температура на выходе активной зоны находится чуть выше данных АЭС, в то время как

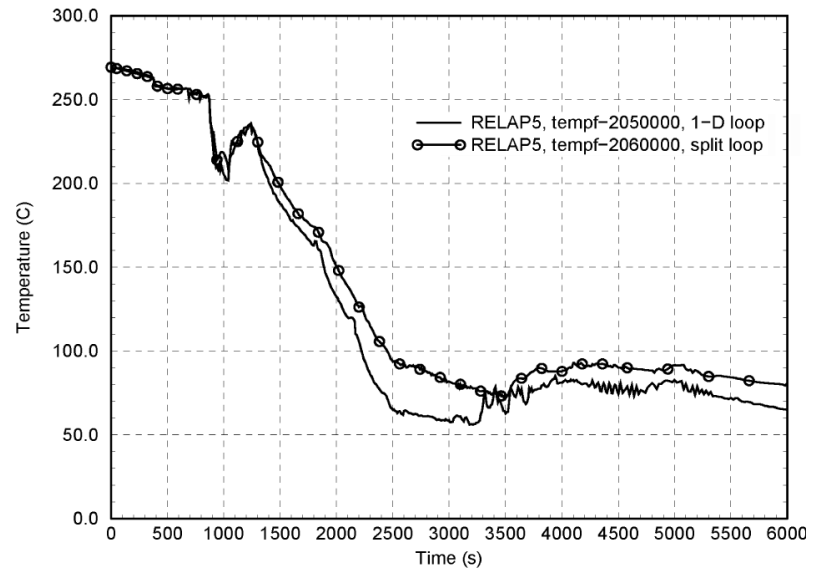

Рис. 22. Температура в опускном участке под патрубком холодной нитки петли № 1 на уровне верха активной зоны напротив сварного шва № 4 корпуса реактора для

базовой и двухуровневой модели холодных ниток для одномерной модели ГЦТ - чуть ниже. Опираясь на представленную информацию можно признать, что подход к моделированию холодных ниток одним уровнем гидравлических объемов по высоте более консервативен с точки зрения оценки термошока корпуса реактора.

\section{Выводы}

В целом моделирование расслоения в ГЦТ путем разбиения ниток по высоте в рамках одномерного расчетного кода является возможным, на что указывают данные проведенного расчетного анализа. Отсутствие трения и «зацепления» потоков одномерных объемов в одном канале приводит к преувеличению перемешиваемости как внутри ГЦТ, так и в опускном участке реактора. Расслоение в холодных нитках при подаче воды САОЗ может быть смоделировано удовлетворительно. При данном моделировании можно избежать паразитных эффектов разворота направления циркуляции в петлях. Однако полная симуляция распределения потоков внутри нитки проблематична.

Моделирование горячих ниток разбиением петель по высоте требует соответствующего разбиения модели реактора, что, исходя из узкого применения таких моделей, не оправданно. Более того, при формировании основных условий охлаждения в холодных нитках, численная схема расчетного кода и сама нодализация «размывает» фронты стратификации, что делает проблематичным выявление такого феномена в горячих нитках.

Анализ поведения температур горячих ниток по реальным данным АЭС для течей с подачей САОЗ при низкой тепловой мощности выявил существенную стратификацию теплоносителя. Разность температур может достигать $140{ }^{\circ} \mathrm{C}$. Представленный факт необходимо учитывать при оценках прочности аналогичных режимов. Моделирование его в рамках рассмотренного выше подхода требует значительных усилий по переработке модели.

Влияние двухуровневого моделирования ниток ГЦТ, как и ожидалось, приводит к более мягким последствиям с точки зрения охлаждения корпуса реактора за счет более интенсивного перемешивания в петлях. Подход с моделированием одномерных холодных ниток можно считать более консервативным с точки зрения термошока корпуса реактора.

Следует отметить, что проверка различных явлений для данной модели проведена преимущественно в однофазной области, поэтому ее применение, в основном, необходимо осуществлять в обозначенных границах. Например, это могут быть эксплуатационные расчеты. Применение такой модели возможно для оценки некоторых процессов, важных для симптомно-ориентированных аварийных инструкций (СОАИ), где осуществляется подача воды САОЗ или возможны стагнации потока (компенсируемые течи, разрывы паропровода).

\section{Список использованной литературы}

1. Комплексные теплогидравлические анализы для исследования влияния термошока. Разработка теплогидравлической модели реактора ВВЭР-1000 для оценки влияния термошока корпуса реактора с использованием компьютерного кода RELAP5/MOD3.2 (этап № 2, промежуточный): Отчет о НИР / ГНТЦ ЯРБ. - К., 2010 . 
2. Воробьев Ю. Ю. Теплогидравлическая модель реактора ВВЭР-1000 для получения граничных условий при оценке сопротивления хрупкому разрушению с использованием компьютерного кода RELAP5/MOD3.2 / Ю. Ю. Воробьев, О. Р. Кочарьянц // Ядерна та радіаційна безпека. - 2011. - № 2 (50). - С. 13-19.

3. Отчет о расследовании нарушения в работе РАЭС. Незакрытие главного предохранительного клапана ИПУ КД YP21S01 во время плановой проверки работоспособности реальным повышением давления в первом контуре перед пуском энергоблока № 3 после ППР из-за подклинивания в седле золотника импульсного клапана YP21S04 после его открытия: Отчет № 3 РОВ-П07-002-09-09Д, ОП РАЭС. - 2009.

4. International Comparative Assessment Study of Pressurized Thermal Shock in Reactor Pressure Vessels. NUREG/CR-6651, ORNL/TM-1999/231. - 1999.

5. Structural evaluation of thermal stratification for PWR surge line / Yu Y .J., Park S. H., Sohn G. H. and Bak W. J. // Nucl. Eng. Des. - 1997. - № 178. - P. 211-220.

6. Flow Stagnation and Thermal Stratification in Single and TwoPhase Natural Circulation Loops (Lecture T17) / José N. Reyes Jr.; International Centre for Theoretical Physics (ICTP) Trieste, Italy, June 25 - June 29, 2007.

7. The European project FLOMIX-R: Fluid mixing and flow distribution in the reactor circuit. Final Summary Report. Editor U.Rohde. FZR-432. - August 2005.

8. Reactor Safety Issues Resolved by the 2D/3D Program. International Agreement Report. NUREG/IA-0127, GRS-101, MPR-1346. July 1993.

9. Tuomisto $H$. Thermal-hydraulics of the Loviisa reactor pressure vessel overcooling transients. - Imatran Voima Oy, Research report IVO-A-01/87. - 1987.
10. Pressurized Thermal Shock in Nuclear Power Plants: Good Practices for Assessment Deterministic Evaluation for the Integrity of Reactor Pressure Vessel. IAEA-TECDOC-1627. - Vienna: IAEA, 2010 .

11. Mixing Phenomena of Interest to Boron Dilution During Small Break LOCAs in PWRs / H. P. Nourbakhsh, Z. Cheng // Proceedings of the 7th International Meeting on Nuclear Reactor Thermal-Hydraulics. NURETH-7. NUREG/CP-0142. - Vol. 4. - 1995.

12. Decay of Buoyancy Driven Stratified Layers with Applications to Pressurized Thermal Shock (PTS) / Theofanous T. G., Nourbakhsh H. P., Gherson P., and Iyer K.; U. S. Nuclear Regulatory Commission, NUREG/CR-3700. - May 1984.

13. Flow Stagnation and Thermal Stratification in Single and TwoPhase Natural Circulation Loops (Lecture T17) / José N. Reyes Jr.; International Centre for Theoretical Physics (ICTP) Trieste, Italy, June 25 - June 29, 2007.

14. Ю. Ю. Воробьев, О. Р. Кочарьянц. Валидация теплогидравлической модели реактора ВВЭР-1000 для компьютерного кода RELAP5/MOD3.2 по оценке условий термошока корпуса реактора // Ядерная и радиационная безопасность. - 2011. № 3 (51). - C. 29-37. 